\title{
Nurses Perception of Incentives System in Assiut University Hospital
}

\author{
Ahmed , D ., M ; Yousef , H ., R ; \& Abd Elkhalek , E ., M. \\ Infection Control Unit at Assiut University Hospital \\ Nursing Administration, Faculty of Nursing, Assiut University \\ Public Health \& Community Medicine, Faculty of Medicine, Assiut University
}

\begin{abstract}
:
Background: Incentives play an important role in organizations as it influences a variety of work-related behavior, as well as the motivation of employees. Aim of the study: The present study was conducted in the main Assiut University Hospital to assess nurse's perception about the incentives system. Subject sand Methods: This study included 271 nurses who randomly selected from all units at the main Assiut University Hospital. The study included both quantitative and qualitative methods for data collection. Results: High percent of the participants reported that the most important incentives are fair remuneration, bounces, appropriate working hours, and different services (health/ education). The promotion, appreciation of work efforts, a good relations with colleagues and superior encouragement were the most important morale incentives. This is confirmed by the results of Focus group discussions as about half of the participants especially female nurses considered the morale incentives are more important than the financial one especially the good dealing and the respect from the physicians. Conclusion and Recommendations: In conclusion, this study indicates that nurses know what they want from incentives. Attention to priorities and flexible incentives system may help to create the cohesive work environment that nurses seek. Determine the objectives are the most important factors to increase the effectiveness of the incentive system.
\end{abstract}

\section{Key Words: Incentive System - Nurses- Punishement, Positive Incentives}

\section{Introduction:}

Incentives play an important role in organizations as it influences a variety of work-related behavior, as well as the motivation of employees. Also, it can used to guide behavior and performance in an attempt to attract and retain the best-qualified employees and keep them satisfied and motivated (Gieter et al., 2006). Incentives defined as "all the rewards and punishments that providers face as a consequence of the organizations in which work the institutions under which operate and the specific interventions provide. Also, includes the factors and/or conditions within health professionals' work environments that enable and encourage them to stay in jobs, in profession and in countries (WHO, 2008).

Incentives can be financial or non financial. Financial incentives involve the transfer of monetary values, such as salaries, pensions, bonuses, allowances and loans. Non financial incentives include work autonomy, flexible hours, and scheduling, coaching and mentoring structures, support for career development, safe and clear workplaces, vacation days, study leave, planned career breaks, occupational health and counseling services, recreational facilities, equal opportunity policy, enforced protection of pregnant women against discrimination \& parental, Also incentives may be positive which involve finance such as salaries, pensions, bonuses, allowances, psychological such as social support, respect\& negative incentive such as punishment (WHO, 2008).

Nurses who feel treated fairly are most likely to give their education, experience, and effort to remain their jobs and would respond to the use of incentive with optimism and this sense of optimism would have a positive impact on their commitment to the hospital, while those, who feel unfairly treated are most likely to look for other jobs (Mantler and Armstrong, 2006). In other words, incentives may increase a person's effort; generally, it is thought that monetary incentives will increase effort and performance (Bonner et al., 2002).

Effective incentive systems present a well designed and supported package, involve input from all relevant stakeholders in the design phase, embrace the principles of transparency, fairness and consistency, fit the purpose for which are intended and maintain the strategic impact of the incentive components, employ a combination of financial and non-financial incentives, carry out regular and systematic reviews and evaluate impact \& motivate the target population (WHO, 2008).

The problem lies in the ability to measure and document the differences between the employees. This is a normal reason why incentive systems sometimes fail. The lack of objective criteria and measurement spreads mistrust among the employees towards management. Different departments within an organization may have different conditions to achieve good results, depending on what job 
assignment have. This may cause jealousy (Duberg, 2009).

\section{Significance of the study}

Good incentive system encourages employees to be productive, creative and stimulates innovation. Incentive systems reside within organizations include its structure, rules, human resources management, opportunities, internal benefits, rewards and sanctions. Incentives can be positive, negative, financial or non financial, tangible or intangible (ICN, 2007). Based on reality, organizational incentive systems have a significant influence on the overall performance of individuals and the organization (Wignaraja, 2006).

Due to absence of studies carried out at Upper Egypt about incentive system for nurses, it was felt necessary to assess nurses' perception of hospital incentive system in an attempt to shed light in this area helping to motivate, satisfy and improve the performance of employees.

\section{Aims of the study:}

The present study was conducted in the main Assiut University Hospital to assess nurse's perception about the incentives system.

Subject and methods:

Design: This study was performed by using cross sectional design and Focus Group Discussions (FGDs) during period from February to May 2012.

Study setting: The present study was conducted in the main Assiut University Hospital including all hospital units that offer incentives which are 23 units and their staff nurses are 572 and only three units do not offer incentives includes 165 nurses.

Sample size: The sample was calculated using EpiInfo statistical package, version 3.3 with power $80 \%$, at $95 \%$ level of confidence (CI), with expected prevalence $50 \%$. Accordingly, sample size was estimated to be $267+10 \%$ individuals to guard against non-response rate. The computed sample size plus expected dropout rate was 295.

Sampling technique: A recent list of all health care units in the main Assiut University Hospital was obtained from hospital administration. 295 nurses selected randomly from total number of 737 working nurses in the units offered incentives or not proportionate to their numbers in each unit. After explanation of the study objectives, 284 nurses (214 from units offer incentives and 70 from units do not offer incentives) agreed to participate in the study with $96 \%$ response rate.

Ethical Consideration: Formal administrative approvals were taken before the start of the study. These included approval by the ethical review committee of Assiut Faculty of Nursing, also include approval by the directorate of the main Assiut
University Hospital. Informed consent is taken from the study participants and confidentiality of data is secured.

Pilot study: Before starting to collect final data, a pilot study was carried out on a sample of 20 (Not included in the study).

Data collection: Data were collected by using both quantitative and qualitative approaches. For quantitative data collection, a semi-structured questionnaire was used for self administered and filled anonymously. The questionnaire included sociodemographic data and work characteristics data. Questions to assess nurse's perception regarding incentives in the main Assiut University Hospital were measured by incentive system questioner that was developed by Shalaby (1997); modified by the researcher to be suitable for the nature of the study. It included 11 questions covering the following data: Types of incentives offered, importance of financial and morale incentives applied at work place and important factors that increase the effectiveness of the incentive system. Response of participant to the questions using 5 likert scales ranged from one (not important) to five (very important).

The focus group discussion guide explored participants' knowledge, experiences, preferences and assumptions about incentives in their work. The guide was tested with a group of nurses not included in the study.

Four focus group discussions were conducted among 27 nurses from units offer incentives and units do not offer incentives, two groups for males and two groups for females. Focus group discussions were carried out in the nurses' room. Groups ranged in size from 6-9 participants and each session lasted 45-60 minutes. Moderator used the protocol to ask openended questions and probe response. Prior to each discussion the researcher ensured the issue of confidentiality and they also made sure that there was a relaxed atmosphere before the discussion started. The note taker documented the sessions whether verbal or non-verbal aspects. The all sessions were audio taped after taking permission of the participants.

Data Analysis: For quantitative data: Questionnaires were reviewed and excluded 13 incomplete instruments, so 271 questionnaires were entered into Excel program. Data analyzed using SPSS version 16. The frequencies, the percentages, the mean and the standard deviation were computed. Chi-squared test was used as the test of significance; $\mathrm{P}<0.05$ was considered significant.

For qualitative data: The FGDs were translated into English by the researchers. Coded material was compared and organized into themes that were then grouped into central categories. The information in 
each FGD was summarized and grouped according to these predefined information categories.

\section{Results:}

Table (1) shows the socio-demographic characteristics of nurses in the present study. The total studied sample was 271 nurses their mean age was $29.9 \pm 7.3$ years. The vast majority of the respondents $(91.5 \%)$ were females and $89.7 \%$ had children ranged from one to six children and $69 \%$ were married and $53.1 \%$ of them were residents of rural areas.

As regards the educational level of respondents, Figure (1) demonstrates that $71.6 \%$ of them graduated from nursing secondary schools, $15.5 \%$ graduated from Heath Technical Institute, $11.4 \%$ had Bachelor of Nursing and few of them (1.5\%) were postgraduates.

As shown in Table (2) and Figure (2), more than three quarters of the respondents worked in units offers incentives compared with $23 \%$ in units do not offer incentives. Staff nurses represented $71.6 \%$ of the sample. Nearly $\mathbf{4 2 \%}$ worked more than 10 years. The vast majority of studied nurses $(96.3 \%)$ did not work in any place other than the main University Hospital. The public transportation was the main method of transportation to and from the hospital $(74.2 \%)$.

Types of incentives offered in the work place depicted in Table (3). Less than half of the participants $(47.6 \%)$ received positive incentives and $83.7 \%$ of them reported that the positive incentives offered were financial while a morale incentive was reported by $0.6 \%$. High percent of the nurses received negative incentives $(\mathbf{6 8 . 3} \%)$ in the form of sanction

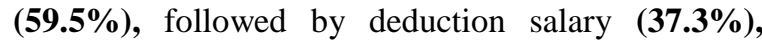
while low percent of them reported inequity $(\mathbf{3 . 2 \%})$. Importance of financial incentives as reported by studied nurses showed in Table (4). High percent of them reported that the most important incentives are fair remuneration, bounces, appropriate working hours, and different services (health/ education) $(69.7 \%, 60.9 \%, 60.5, \% 60.5 \%$, respectively). The promotion, appreciation of work efforts, good relations with colleagues and superior encouragement were the most important morale incentives reported by $77.1 \%, 71.2 \%, 66.8 \%, 64.6 \%$ nurses, respectively.

Perception of studied nurses of incentives system revealed in Table (5). Below half of them (47.2\%) reported that the aim of incentives was to compensate the shortage of the main salary, $78.6 \%$ reported that the incentives system applied at their work place didn't fair, $73.4 \%$ thought that the incentives system applied at their work place need comprehensive change and $64.6 \%$ reported that the incentives system applied at their work place was unclear (Figure 3).

Nurse's satisfaction with incentives showed in Table (6). The majority of nurses $(87.5 \%)$ reported that the incentive system applied in work place did not satisfy basic (actual) needs of employees, for the following reason, administration not caring to study the employees' needs (54.0\%). High percent of them $(81.9 \%)$ reported that the incentive system applied not achieve job security because the following reasons, unsatisfied the actual needs of employees; don't provides incentives on a regular basis and unfairness $(35.1 \%, 20.0 \%, 19.4 \%$, respectively).

\section{Results of Focus Group Discussions (FGDs)}

Characteristics of participants

A total of 27 nurses, 12 males and 15 females participated in the FGDs. The mean age of the participants was 30 years.

\section{Concept of incentives}

In probing how this concept is known by the participants, we observed that the majority of the respondents defined incentives as a way to boost employee productivity "individualized variable pay based on performance”.

\section{Types of incentives}

There was a general opinion among all the participants that incentives offered in the main Assiut University Hospital are financial in the form of profit share and non-financial incentives to keep morale high, reward workers for good effort and meet work goals. Either type should be based on clearly specified behaviors or outputs.

About half of the participants especially female nurses considered the morale incentives more important than the financial one especially the good dealing and the respect from the physicians. One participant said that "The moral incentive is the most important. It should be a difference between who works hard and who does not work. We must encourage the premier even by certificate of appreciation".

Involvement in decision making, conducive work environment, participation in professional conferences, job security, working conditions, or job prestige, this non-wage characteristics of employment are more favorable in the public sector.

A number of nurses demonstrated that "financial incentives, though important, are not the sole reason, and often not the main reason for motivation. Other important motivating factors include recognition, appreciation and opportunities for career advancement."

The bad dealing at work was a general statement that was elaborated by the respondents as a form of negative incentives used by the work supervisors or physicians. Other forms of negative incentives were 
deduction of the main salary wage and inequality and "ignorance" in the dealing by the boss. Double standards is one of the major problems that faced the nurses in their work place provides a model of inequity that can trigger or provoke job dissatisfaction.

The relation between the work performance and incentives

Incentives are certain (if the targeted performance occurs, the employee will receive the extra compensation); the effectiveness of individual monetary incentive systems can be attributed to the fact that when employees are offered individual incentives, with or without guaranteed base pay, the amount they earn in incentive pay is dependent upon the number of units of work they complete.

Pay-for-performance plans, and quality-monitoring systems has ensured that measuring and reporting patient satisfaction is an important part of valuebased health care. Support from opinion leaders of professional organizations is also considered very helpful to promote the work.

About half of the participants reported that there is no relation between the offered incentives and the work performance. They added, payments to nurses are standardized across the main Assiut University without regards to outcomes, quality of care, or years of experience.

Incentives are considered to influence behavior and attitudes but only when the reward criteria are clearly known to the recipients. The nurses' acceptance of management bonuses tended to depend on the direct support provided by the managers. Economic incentives linked to financing conditions of work were seen to be significant for nurses' daily lives. In general, nurses were sensitive to efforts to facilitate or impede their work.

Nurses continued to claim that their interventions could not easily be measured in a relevant manner (quality versus quantity) although standards of practice had been developed and were applied during clinical audit. The potential negative impact of performance-related pay on interpersonal relationships within the nursing and health teams (e.g. competition) was also feared. The physicians received the biggest incentive and the other amount was divided among the team members, the resulting reward may be quite small ("peanuts") and not a sufficient financial incentive.

Rules of incentive distribution:

First, incentives should be based only on the employee's own performance. Benefits as incentives or disincentives are related to job satisfaction, perceived stress, and intent to stay on their current jobs. One nurse said that "I think an additional motivation should be offered to make sure that we are practicing good practice".

Problems in the current incentive system The injustice in the incentive distribution

The governmental hospitals offered more incentive as 60 Egyptian pounds for night shift compared to 25 Egyptian pounds in our University Hospital. So, we feel with inequality and many of them leaves their work and go to work in other places as the private hospital or even travels abroad. There is no clear base to incentive distribution. Lack of motivation of health workers and poor wages were the most important factor affecting health workers' decisions to leave.

Changes after Egypt's revolution and strikes:

After the strike, the financial is better but there are fears from the unsafe working conditions resulting from the accompanying exceeded beat them if in case of death of the patient or objection of nurses on the presence of visitors while giving treatment to patients.

Most of the participants shared in the strike but they refused the general strike and very sad because there were some patients died as a result to the strike.

Recommendations to improve the incentive system Nurses believed that incentives/disincentives facilitates should be changed to make reward systems more likely to be relevant. While many nurses recommended a general increase in salary as the most relevant economic incentive, as much importance was given to the relative salary and its impact on social status as to financial gain. Other suggested economic incentives were modest in nature and may reflect certain personal characteristics of individuals attracted to nursing 
Table (1): Socio-demographic characteristics of the studied nurses in the main Assiut University Hospital, 2012

\begin{tabular}{|c|c|c|}
\hline Items & No. $(n=271)$ & $\%$ \\
\hline \multicolumn{3}{|l|}{ Age: (years) } \\
\hline$<25$ years & 79 & 29.2 \\
\hline $25-<30$ & 61 & 22.5 \\
\hline $30-<35$ & 50 & 18.5 \\
\hline$\geq 35$ years & 81 & 29.9 \\
\hline Mean \pm SD (Range) & \multicolumn{2}{|c|}{$29.87 \pm 7.34(19-58)$} \\
\hline \multicolumn{3}{|l|}{ Sex: } \\
\hline Male & 23 & 8.5 \\
\hline Female & 248 & 91.5 \\
\hline \multicolumn{3}{|l|}{ Place of residence: } \\
\hline Rural & 144 & 53.1 \\
\hline Urban & 127 & 46.9 \\
\hline \multicolumn{3}{|l|}{ Marital status: } \\
\hline Single & 77 & 28.4 \\
\hline Married & 187 & 69.0 \\
\hline Widow & 4 & 1.5 \\
\hline Divorced & 3 & 1.1 \\
\hline \multicolumn{3}{|l|}{ Having children: $(n=194)$} \\
\hline Yes & 174 & 89.7 \\
\hline No & 20 & 10.3 \\
\hline \multicolumn{3}{|l|}{ Number of children: } \\
\hline One & 28 & 16.1 \\
\hline Two & 55 & 31.6 \\
\hline Three & 61 & 35.1 \\
\hline 4 or more & 30 & 17.2 \\
\hline Mean \pm SD (Range) & \multicolumn{2}{|c|}{$2.6 \pm 1.1(1-6)$} \\
\hline Type of accommodation: & & \\
\hline Ownership & 191 & 70.5 \\
\hline Rent & 80 & 29.5 \\
\hline
\end{tabular}

Fig. (1): Educational level of the studied nurses in the main Assiut University Hospital, 2012

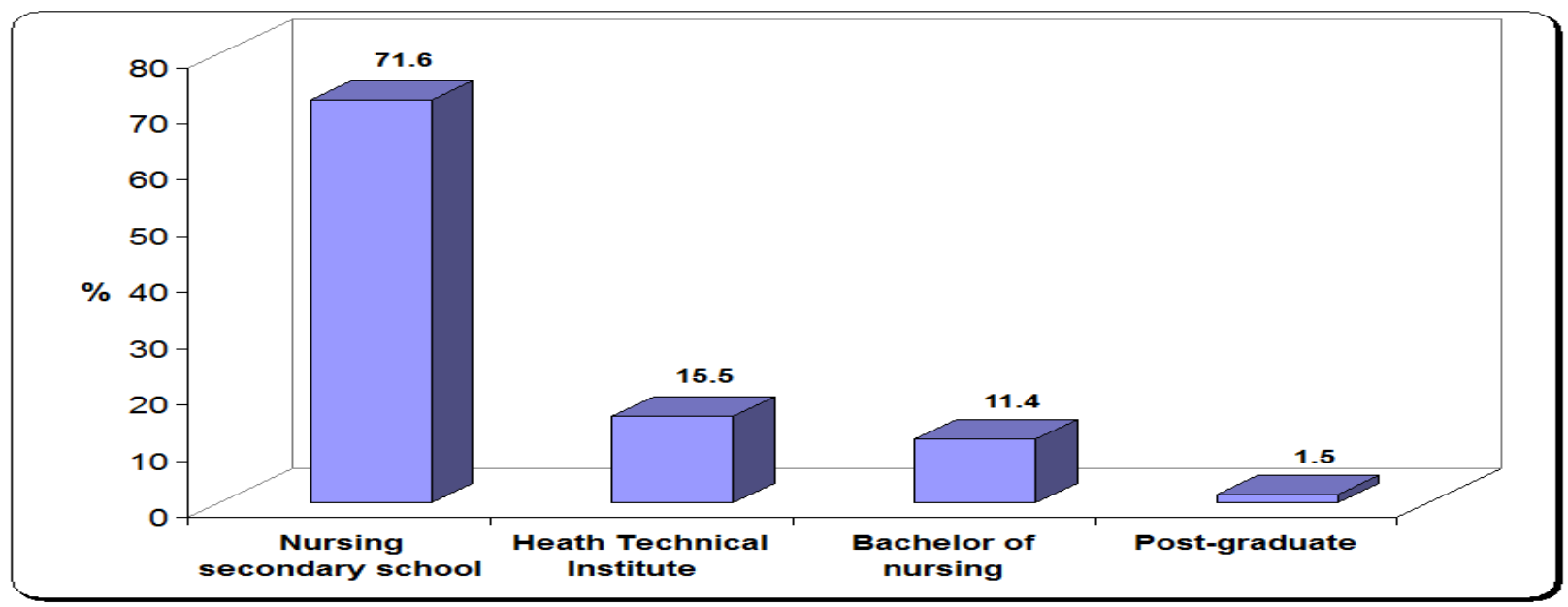


Table (2): Work characteristics of the studied nurses in the main Assiut University Hospital, 2012

\begin{tabular}{|l|c|c|}
\hline \multicolumn{1}{|c|}{ Items } & No. $(\mathbf{n}=\mathbf{2 7 1})$ & $\%$ \\
\hline Work status: & & 12.9 \\
\hline Head nurse & 42 & 15.5 \\
\hline Associate nurse & 194 & 71.6 \\
\hline Staff nurse & & 17.7 \\
\hline Years of experience: & 48 & 38.4 \\
\hline Less than 5 years & 104 & 43.9 \\
\hline 5 - 10 years & 119 & 3.7 \\
\hline > 10 years & & 96.3 \\
\hline Working in a place other than the hospital: & 10 & \\
\hline Yes & 261 & 10.0 \\
\hline No & & 20.0 \\
\hline Place of working: (n= 10) & 1 & 70.0 \\
\hline Pharmacy & 2 & \\
\hline Private hospital & 7 & 1.8 \\
\hline Private clinic & & 3.0 \\
\hline Method of transportation to/from hospital: & 5 & 4.4 \\
\hline On foot & 12 & 16.6 \\
\hline Private car & 45 & 74.2 \\
\hline Motorcycle & 201 & \\
\hline Hospital's bus & & \\
\hline Public transportation & & \\
\hline
\end{tabular}

Fig. (2): Distribution of the studied nurses according to offering incentives or not in the main Assiut University Hospital, 2012

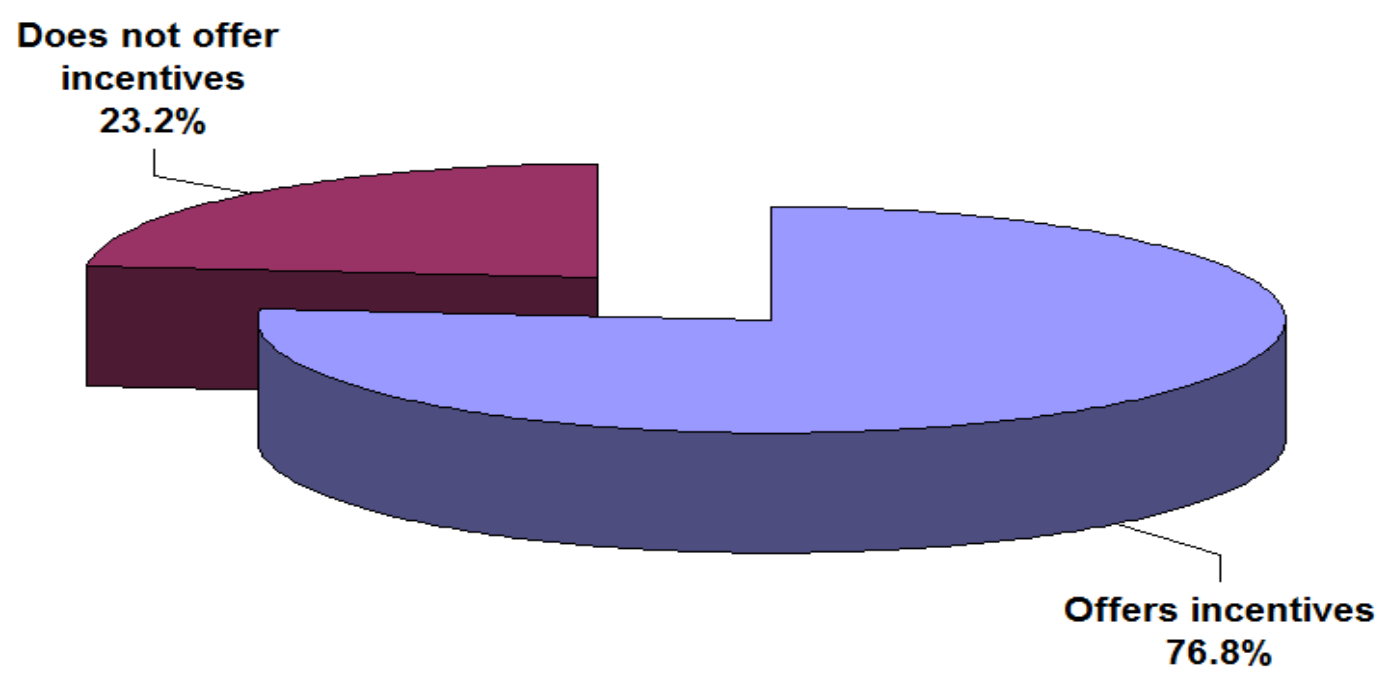


Table (3): Perception of the participants regarding types of incentives offered at the main Assiut University Hospital, 2012

\begin{tabular}{|l|c|c|}
\hline \multicolumn{1}{|c|}{ Items } & No. $(\mathbf{n}=\mathbf{2 7 1})$ & \% \\
\hline Positive incentives in work place: & & 47.6 \\
\hline Yes & 129 & 52.4 \\
\hline No & 142 & 83.7 \\
\hline Types of positive incentives (n= 129): & 108 & 0.6 \\
\hline Financial & 8 & 10.1 \\
\hline Morale & 13 & 68.3 \\
\hline Others & & 31.7 \\
\hline Negative incentives in work place: & 185 & \\
\hline Yes & 86 & 59.5 \\
\hline No & & 37.3 \\
\hline Types of negative incentives: (n= 185) & 110 & 14.6 \\
\hline Sanction & 69 & 10.8 \\
\hline Deduction from salary & 27 & 3.2 \\
\hline Bad dealing by doctors & 20 & 14.6 \\
\hline Cancellation of paid vacation & 6 & \\
\hline Inequity & 27 & 13.3 \\
\hline Do not know & & 0.7 \\
\hline The most effective type of incentives: & 36 & 69.4 \\
\hline Positive incentives & 2 & 16.6 \\
\hline Negative incentives & 188 & 45 \\
\hline Both & & \\
\hline Do not know & & \\
\hline
\end{tabular}

Table (4): Importance of positive incentives as reported the participants at the main Assiut University Hospital, 2012

\begin{tabular}{|c|c|c|c|c|c|c|c|c|c|c|}
\hline & \multicolumn{2}{|c|}{$\begin{array}{c}\text { Most } \\
\text { important }\end{array}$} & \multicolumn{2}{|c|}{ Very important } & \multicolumn{2}{|c|}{ Important } & \multicolumn{2}{|c|}{$\begin{array}{c}\text { Important to } \\
\text { some extent }\end{array}$} & \multicolumn{2}{|c|}{$\begin{array}{c}\text { Not } \\
\text { important }\end{array}$} \\
\hline & No. & $\%$ & No. & $\%$ & No. & $\%$ & No. & $\%$ & No. & $\%$ \\
\hline \multicolumn{11}{|l|}{ Financial incentives } \\
\hline Appropriate working hours & 118 & 43.5 & 61 & 22.5 & 44 & 16.2 & 20 & 7.4 & 28 & 10.3 \\
\hline $\begin{array}{l}\text { Different services (health/ } \\
\text { education) }\end{array}$ & 144 & 53.1 & 59 & 21.8 & 46 & 17.0 & 18 & 6.6 & 4 & 1.5 \\
\hline Participation in profits & 164 & 60.5 & 77 & 28.4 & 16 & 5.9 & 5 & 1.8 & 9 & 3.3 \\
\hline Working conditions & 164 & 60.5 & 76 & 28.0 & 20 & 7.4 & 9 & 3.3 & 2 & 0.7 \\
\hline Bounces & 165 & 60.9 & 70 & 25.8 & 24 & 8.9 & 10 & 3.7 & 2 & 0.7 \\
\hline Fair remuneration & 189 & 69.7 & 39 & 14.4 & 22 & 8.1 & 8 & 3.0 & 13 & 4.8 \\
\hline \multicolumn{11}{|l|}{ Morale incentives } \\
\hline $\begin{array}{l}\text { Participation in the } \\
\text { administrative work }\end{array}$ & 113 & 41.7 & 74 & 27.3 & 51 & 18.8 & 19 & 7.0 & 14 & 5.2 \\
\hline $\begin{array}{l}\text { A good relations with } \\
\text { colleagues }\end{array}$ & 181 & 66.8 & 66 & 24.4 & 20 & 7.4 & 3 & 1.1 & 1 & 0.4 \\
\hline Promotion & 209 & 77.1 & 47 & 17.3 & 8 & 3.0 & 5 & 1.8 & 2 & 0.7 \\
\hline $\begin{array}{l}\text { Appreciation of work } \\
\text { efforts }\end{array}$ & 193 & 71.2 & 55 & 20.3 & 17 & 6.3 & 2 & 0.7 & 4 & 1.5 \\
\hline Superior encouragement & 193 & 71.2 & 55 & 20.3 & 17 & 6.3 & 2 & 0.7 & 4 & 1.5 \\
\hline
\end{tabular}


Table (5): Nurses' perception of incentives system in the main Assiut University Hospital, 2012

\begin{tabular}{|c|c|c|}
\hline Items & No. $(n=271)$ & $\%$ \\
\hline \multicolumn{3}{|l|}{ Aims of the incentives: } \\
\hline Compensate the shortage of the main salary & 128 & 47.2 \\
\hline Employee performance & 95 & 35.7 \\
\hline Both & 37 & 13.7 \\
\hline Do not know & 11 & 4.1 \\
\hline \multicolumn{3}{|l|}{$\begin{array}{l}\text { Do you think that the incentives system applied at your work } \\
\text { place is transparent enough for the workers? }\end{array}$} \\
\hline Transparent & 18 & 6.6 \\
\hline Transparent some extent & 78 & 28.8 \\
\hline Not transparent & 175 & 64.6 \\
\hline \multicolumn{3}{|l|}{$\begin{array}{l}\text { Do you agree that the incentives system applied at your work } \\
\text { place fair and equitable? }\end{array}$} \\
\hline Yes & 58 & 21.4 \\
\hline No & 213 & 78.6 \\
\hline \multicolumn{3}{|l|}{ Reasons of non justice: $(n=213)$} \\
\hline Does not commensurate with the work effort & 113 & 41.6 \\
\hline Does not distinguish between the active and inactive employees & 77 & 28.4 \\
\hline Does not encourage the required needs from the point of view & 23 & 8.4 \\
\hline \multicolumn{3}{|l|}{ The current incentives system: } \\
\hline Does not need to be changed. & 2 & 0.7 \\
\hline Needs to be changed to some extent. & 70 & 25.8 \\
\hline Needs a comprehensive change. & 199 & 73.4 \\
\hline
\end{tabular}

Fig. (3): Nurses' perception of incentives system characteristics in the main Assiut University Hospital, 2012

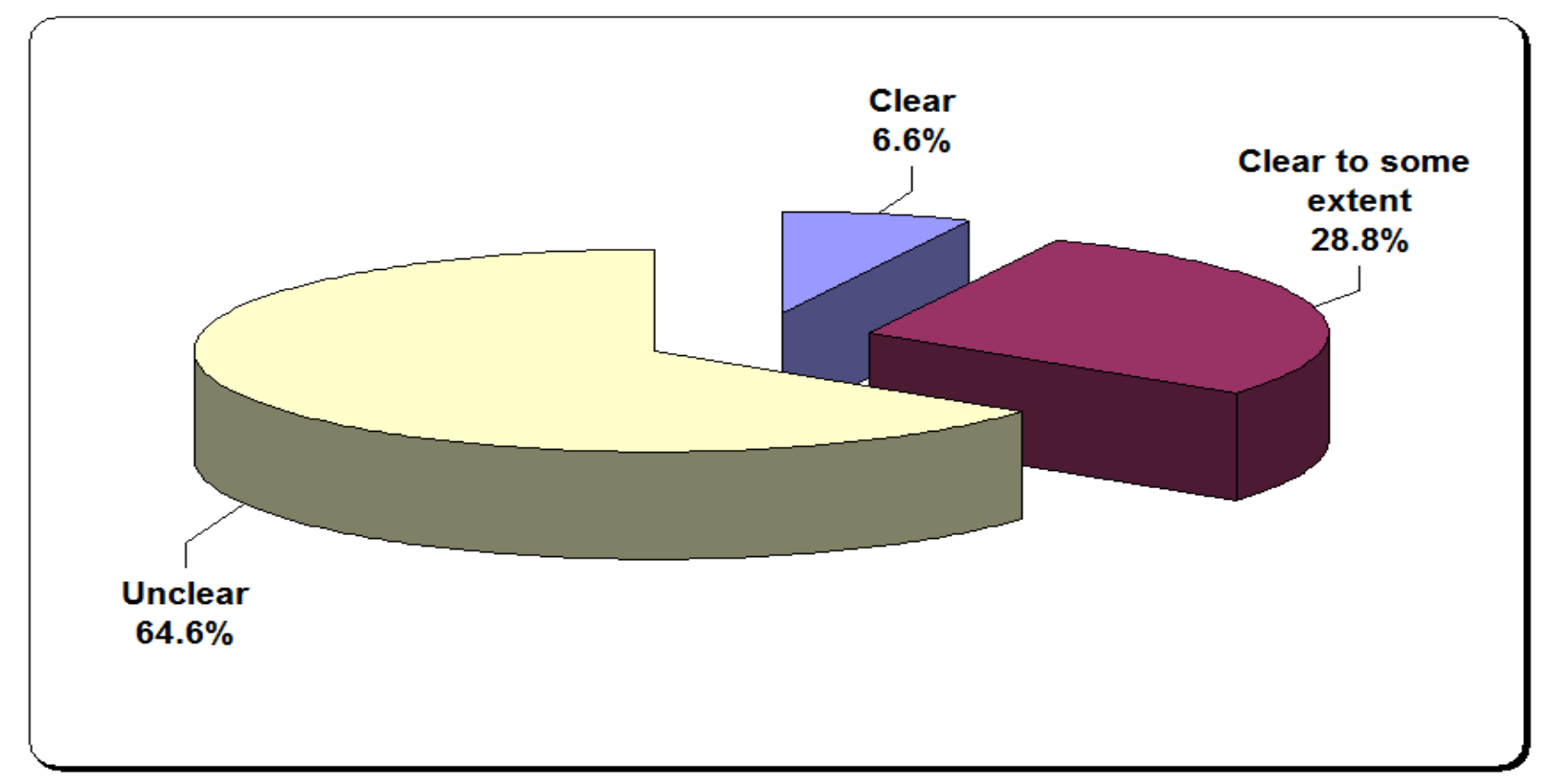


Table (6): Nurses' satisfaction with incentives in the main Assiut University Hospital, 2012

\begin{tabular}{|c|c|c|}
\hline Items & No. $(n=271)$ & $\%$ \\
\hline \multicolumn{3}{|l|}{$\begin{array}{l}\text { Do you think that the incentives system applied in your work } \\
\text { satisfies actual needs of nurses? }\end{array}$} \\
\hline Yes & 34 & 12.5 \\
\hline No & 237 & 87.5 \\
\hline \multicolumn{3}{|l|}{ If Yes, what are the reasons? $(n=34)$} \\
\hline $\begin{array}{l}\text { The system changes to achieve the constant saturation for } \\
\text { these needs. }\end{array}$ & 14 & 41.2 \\
\hline $\begin{array}{l}\text { The ability of individuals to communicate their wishes and } \\
\text { needs, which reflect the satisfaction. }\end{array}$ & 13 & 38.2 \\
\hline $\begin{array}{l}\text { Ongoing study by management to the needs and motivations } \\
\text { of employees. }\end{array}$ & 7 & 20.6 \\
\hline \multicolumn{3}{|l|}{ If No, what are the reasons? $(n=237)$} \\
\hline $\begin{array}{l}\text { The hospital administrators not caring to study the } \\
\text { employees needs. }\end{array}$ & 128 & 54.0 \\
\hline $\begin{array}{l}\text { The system is applied without consideration of the actual } \\
\text { needs of the employees. }\end{array}$ & 117 & 49.4 \\
\hline Employees incapable to express their wishes and opinions. & 74 & 31.2 \\
\hline \multicolumn{3}{|l|}{$\begin{array}{l}\text { Do you think that the incentives system achieves the nurses' } \\
\text { job security? }\end{array}$} \\
\hline Yes & 49 & 18.1 \\
\hline No & 222 & 81.9 \\
\hline \multicolumn{3}{|l|}{ If no, what are the reasons? $(n=222)$} \\
\hline Unsatisfied the actual needs of employees & 95 & 35.1 \\
\hline Does not provide incentives on a regular basis & 54 & 20.0 \\
\hline Unfair & 52 & 19.4 \\
\hline Inflexible & 36 & 13.3 \\
\hline
\end{tabular}

\section{Discussion:}

Today's policy makers, planners and managers are challenged to identify and apply a combination of financial and non financial incentives that are responsive and effective in meeting policy objectives related to recruitment and retention (ICN, 2007a). Incentives and incentive systems are fundamental to developing capacities and translating these capacities into better performance (Wignaraja, 2006).

From the findings of the present study, $77 \%$ of the respondents received incentives from their work places but $47.6 \%$ reported that positive incentives offered in their work place either financial or non financial. On the other hand, more than two thirds of the respondents reported negative incentives in the form of sanction, deduction from salary, bad dealing by doctors etc. $13.3 \%$ believed that positive incentives are more effective than the negative ones but $69.4 \%$ thought the both types of incentives are required in the work place. A study exploring the factors affecting motivation of health workers in six African countries found that poor wages in countries like
Uganda and Zimbabwe were the most important factor affecting health workers' decisions to migrate. However, in Cameroon wages factored below "lack of promotional opportunities, poor living conditions and a desire to gain experience" as the reasons workers decided to leave (Stilwell et al., 2004).

In the present study, high percent of nurses reported that the most important incentives are fair remuneration, bounces, appropriate working hours, and different services. The promotion, appreciation of work efforts, a good relations with colleagues and superior encouragement were the most important morale incentives reported by more than two third. Also, from the Focus Group Discussions about half of the participants especially female nurses considered the morale incentives are more important than the financial one especially the good dealing and the respect from the physicians. These results are agreed with other studies that demonstrated financial incentives, though important, are not the sole reason, and often not the main reason, for motivation. Other important motivating factors include recognition, appreciation and opportunities for career 
advancement (Dieleman and Harnmeijer, 2006). Non-financial rewards are particularly vital for countries and organizations where limited funding constrains their capacity to provide financial rewards (Alamri, 2011). This is on the same line with the study findings of ICN (2008) as non-financial incentives, involving work autonomy, flexibility hours and scheduling, recognition of work and support for career development, etc.) Play an equally crucial role. This is in well resourced countries where staff is able to maintain a high standard of living, as well as in relatively poorly resourced ones.

Wieck et al. (2009) found that the most important incentives were the work environment described as cohesive work environment: working with people who help you, share the work and pull together as a team. The least important preferences were fairly consistent across generations: luxury items, day care, and subsidized transportation.

The majority of nurses in our study reported that the incentive system applied in work place did not satisfy basic needs of employees. Only $0.7 \%$ of them satisfied by the present incentives system. This is in consistence with the findings of other study conducted by Wieck et al. (2009) as they found that over three-quarters $(78.5 \%)$ satisfied by their incentives system. Also, it is consistent with the findings of Armstrong and Cameron (2005) as the salary inequity is clearly the major barrier for recruitment and retention as indicated by both nurse leaders and front-line staff. Nurses' perceptions of rewards and their possible impacts have been examined by Kingma (2003) using individual interviews, focus groups and observations. She identified two main categories of economic rewards: the financial incentives (e.g. salary and petrol allowance) involved a monetary transfer to the nurses, whereas the financed rewards (e.g., subsidized continuing education and paid sabbatical leave) represented a cost for the employer without any monetary transfer to the nurses themselves.

From the findings of the present study, $78.6 \%$ of the respondents confirmed the current incentive system does not achieve justice, this is due to for the following reasons, does not commensurate with the work effort $(41.6 \%)$ and does not distinguishes between the active and inactive employees (28.4\%).

In Focus Group Discussions about half of the participants especially female nurses considered the feel with inequality and many of them leaves their work and go to work in other places as the private hospitals or even travels abroad, there is no clear base to incentive distribution. These results are agreed with other studies that demonstrated that the fairness in distribution the incentives affects the manner in which individuals view their jobs and the organization, and it can affect the amount of effort they expend in accomplishing tasks (Kingma, 2003). An open procurement process, fair treatment in awarding the contract to the best bid, is important in building investor confidence (Ajayi et al., 2002).

In the present study, high percent of respondents $(81.9 \%)$ believed that the incentive system applied in main Assiut university hospital did not achieve job security, this is due to the following reasons, unsatisfied the actual needs of employees, do not provides incentives on a regular basis and unfair $(35.1 \% 20.0 \%, 19.4 \%$, respectively). This is consistent with study found out the reasons behind the request of nurses move outside the hospital, the findings showed that the vast majority of the respondents believe that the basic requirements, and services, and facilities provided by the hospital is one of the main reasons behind their desire to move, as well as ventilation and amplitude and public services, leisure and material and morale incentives is one of the reasons behind the request to move (Khleifat et al., 2013).

From the findings of the present study, below half of the studied nurses reported that the incentives aim to compensate the lack of basic wage $(42,2 \%)$. In congruence with these findings of Pritchard et al. (2010) found that the monetary incentives effect on goal choice, goal commitment, and task performance. In Focus Group Discussions about half of the participants reported that there is no relation between the offered incentives and the work performance. They added that currently payments to nurses for their services are standardized across the main Assiut University without regards to outcomes, quality of care, or years of experience. Results are agreed with other studies that demonstrated pay for performance can (when implemented properly) be positive and deliver performance improvement, especially when it gives financial reward to employees for reasons of both equity and recognition and gives direction to employees by aligning rewards with the organization's goals and objectives. It is based on the performance of groups, individual performance and rewarded by honors. In short, total reward programs, which integrate both financial and non-financial incentives to reward staff, can offer an organization the building blocks to help incentives, recognize and motivate employees to deliver improved levels of performance (Gieter, 2006).

Respondents recommended some issues to improve the current incentive system in the main Assiut University Hospital such as general increase in salary as the most relevant economic incentive, as much importance was given to the relative salary and its impact on social status as to financial gain. Improving nurses' work environments, including 
nurse staffing, meals and safe working environments. Other researchers have shown that a positive working environment is an important element in efforts to recruit and retain staff (Buchan, 1999; Gilson et al. 2004; ICN 2007b). This includes providing a safe working environment for staff and proactively responding to emerging risks, as well as creating a positive organizational culture can play a role in providing a positive environment where people will want to work.

\section{Conclusion:}

Less than half of the participants received positive incentives in the form of financial rewards. The promotion, appreciation of work efforts, good relations with colleagues and superior encouragement were the most important morale incentives reported by participants. Both the qualitative and quantitative data revealed that a number of psychological and non-financial rewards were important for nurses in addition to their monthly pay and other remunerations.

\section{Recommendations:}

- The study recommended that:

- Achieve justice in distribution of incentives.

- Integrating between different types of incentives system should include incentives on the financial and morale especially the promotion, appreciation of work efforts, good relations with colleagues and superior encouragement together.

- Determine of the incentive system objectives are the most important factors to increase the effectiveness of the incentive system.

- Periodic assessment of incentives must to examine the efficiency and utility of it.

- Graduation in employee punishing to does not lose its effectiveness.

\section{References:}

1. Ajayi O, Franzel S, Kuntashula $\mathbf{E}$ and Kwesiga F (2002): Adoption of improved fallow soil fertility management practices in Zambia. Synthesis and Emerging Issues; 59 (3): 317-326.

2. Alamri M (2011): Financial incentives system for nursing in the Kingdom of Saudi Arabia, Journal of Accounting and Finance; 11(2): 5355.

3. Armstrong-Stassen M and Cameron S (2005): Concerns, satisfaction and retention of Canadian community health nurses. Journal of Community Health Nursing; 22 (4): 181-194.

4. Bonner S and Sprinkle G (2002): The effects of monetary incentives on effort and task performance: Theories, evidence, and a framework for research. Accounting, Organizations and Society; 27(4-5): 303-345.

5. -Buchan J (1999): 'Still attractive after all these years? Magnet hospitals in a changing healthcare environment', Journal of Advanced Nursing, vol. 30 Issue 1, pp.100-108.

6. -Dieleman $M$ and Harnmeijer $J$ (2006): Improving health worker performance: in search of promising practices. Geneva, Pp17. At website:

KIT_Publicaties_output/ http://www.kit.nl/net/

ShowFile2.aspx?e=1174

7. Duberg C (2009): Reward system, Health care, Geriatric care, the view of leader, Drawbacks of reward systems; 25-27. gupea.ub.gu.se/bitstream/2077/21844/1/gupea_2 077_21844_1.pdf

8. Gieter S, Pepermans R, Caers $\mathbf{R}$ and Jegers $M$ (2006): Identifying nurses' rewards: a qualitative categorization study in Belgium. Human Resources for Health; 4- 15.

9. Gilson L, Khumalo G, Erasmus E, Mbatsha $\mathbf{S}$ and Mc Intyre D (2004): Preliminary national overview report: South Africa, Health Economics and Exploring the influence of workplace trust over health worker performance Financing Program Working. London School of Hygiene and Tropical Medicine; 4- 6.

10. ICN (2007a): Positive practice environments: quality workplaces quality patient care, ICN, Geneva, accessed 19 February 2008.

11. ICN (2007b): Incentives and the recruitment/retention of nurses, A paper presented at National Experiences in Assessing and Reducing Shortcomings and Negative Trends Affecting Human Resources of the Health System: An International Symposium on Health Workforce Pp.10-12, Lisbon, Portugal.

12. ICN (2008): Guidelines: incentives for health professionals, Pp27: 101.

13. Khleifat $\mathbf{S}$, Elhabaha $M$, and Ataiwrh $\mathbf{Y}$ (2013): Reasons for working in the hospitals desire Princess Haya Bint Al Hussein, the transition to outside hospital, the Jordanian Ministry of Health, Jordan, pp 1-2.

14. Kingma M (2003): Nursing and Health Policy, International Council of Nurses, Human Resources for Health Journal; 1 (2): 1-12.

15. Mantler $\mathbf{J}$ and Armstrong $M$ (2006): Reactions of hospital staff nurses to recruitment incentives. Western Journal of Nursing Research; (37):7073.

16. -Pritchard, Michael I. Curts. (2010): The influence of goal setting and financial incentives on task performance, Organizational Behavior 
and Human Performance, Volume 34, Issue 3, Pages 283-419, Elsevier B.V. Inc

17. Stilwell B, Diallo K, Zurn P, Vujicic M, Adams O and Dal Poz M. (2004): Migration of health-care workers from developing countries: strategic approaches to its management. Bulletin of the World Health Organization; 82:595-600.

18. WHO (2008): World Health Report health systems, improving performance; 61

19. Wieck K, Dols J and Northam S (2009): What nurses want: The nurse incentives project? Nursing Economics; 27 (3): 169-201.

20. Wignaraja K (2006): Competitiveness in a rapidly globalizing economy: Lessons of experience", Mimeo International Labour Organization; 17-18, Geneva. 